\title{
A comparison of chloroplast genome sequences in Aconitum (Ranunculaceae): a traditional herbal medicinal genus
}

\author{
Hanghui Kong ${ }^{1,2}$, Wanzhen Liu ${ }^{3}$, Gang Yao ${ }^{4}$, Wei Gong ${ }^{\text {Corresp. } 3}$ \\ ${ }^{1}$ Key Laboratory of Plant Resources Conservation and Sustainable Utilization, South China Botanical Garden, Chinese Academy of Sciences, Guangzhou, \\ China \\ 2 Guangdong Provincial Key Laboratory of Applied Botany, South China Botanical Garden, Chinese Academy of Sciences, Guangzhou, China \\ 3 College of Life Sciences, South China Agricultural University, Guangzhou, China \\ ${ }^{4}$ College of Forestry and Landscape Architecture, South China Agricultural University, Guangzhou, China
}

Corresponding Author: Wei Gong

Email address: wgong@scau.edu.cn

The herbal medicinal genus Aconitum L., belonging to the Ranunculaceae family, represents the earliest diverging lineage within the eudicots. It currently comprises of two subgenera, $A$. subgenus Lycoctonum and $A$. subg. Aconitum. The complete chloroplast (cp) genome sequences were characterized in three species: $A$. angustius, $A$. finetianum, and A. sinomontanum in subg. Lycoctonum and compared to other Aconitum species to clarify their phylogenetic relationship and provide molecular information for utilization of Aconitum species particularly in Eastern Asia. The length of the chloroplast genome sequences were 156,109 bp in A. angustius, 155,625 bp in A. finetianum and 157,215 bp in $A$. sinomontanum, with each species possessing 126 genes with 84 protein coding genes (PCGs). While genomic rearrangements were absent, structural variation was detected in the LSC/IR/SSC boundaries. Five pseudogenes were identified, among which $\psi_{r p s 19}$ and $\psi_{y c f 1}$ were in the LSC/IR/SSC boundaries, $\psi_{\text {rps } 16}$ and $\psi_{\text {infA }}$ in the LSC region, and $\psi_{y c f 15}$ in the IRb region. The nucleotide variability (Pi) of Aconitum was estimated to be 0.00549 , with comparably higher variations in the LSC and SSC than the IR regions. Eight intergenic regions were revealed to be highly variable and a total of 58 - 62 simple sequence repeats (SSRs) were detected in all three species. More than $80 \%$ of SSRs were present in the LSC region. Altogether, $64.41 \%$ and $46.81 \%$ of SSRs are mononucleotides in subg. Lycoctonum and subg. Aconitum, respectively, while a higher percentage of di-, tri-, tetra-, and pentaSSRs were present in subg. Aconitum. Most species of subg. Aconitum in Eastern Asia were first used for phylogenetic analyses. The availability of the complete cp genome sequences of these species in subg. Lycoctonum will benefit future phylogenetic analyses and aid in germplasm utilization in Aconitum species. 
1 A comparison of chloroplast genome sequences in Aconitum (Ranunculaceae): a traditional

2 herbal medicinal genus

3

4 Hanghui Kong ${ }^{1,4}$, Wanzhen Liu ${ }^{2 *}$, Gang $\mathrm{Yao}^{3}$, Wei Gong ${ }^{2 \#}$

5

$6{ }^{1}$ Key Laboratory of Plant Resources Conservation and Sustainable Utilization, South China

7 Botanical Garden, Chinese Academy of Sciences, Guangzhou 510650, China

$8{ }^{2}$ College of Life Sciences, South China Agricultural University, Guangzhou, 510614, China

93 College of Forestry and Landscape Architecture, South China Agricultural University,

10 Guangzhou, 510614, China

$11{ }^{4}$ Guangdong Provincial Key Laboratory of Applied Botany, South China Botanical Garden,

12 Chinese Academy of Sciences, Guangzhou 510650, China

14 Corresponding author

$15 *$ These authors contributed equally to this work

16 \# Corresponding Author: Wei Gong

17 College of Life Sciences, South China Agricultural University, Guangzhou 510614, China

18 E-mail: wgong@scau.edu.cn

19 Tel: +86 20-37088127; Fax: +86 20-37088127 
24

25

26

\section{Abstract}

The herbal medicinal genus Aconitum L., belonging to the Ranunculaceae family, represents the earliest diverging lineage within the eudicots. It currently comprises of two subgenera, $A$. subgenus Lycoctonum and A. subg. Aconitum. The complete chloroplast (cp) genome sequences were characterized in three species: A. angustius, A. finetianum, and A. sinomontanum in subg. Lycoctonum and compared to other Aconitum species to clarify their phylogenetic relationship and provide molecular information for utilization of Aconitum species particularly in Eastern Asia. The length of the chloroplast genome sequences were 156,109 bp in A. angustius, 155,625 bp in A. finetianum and 157,215 bp in A. sinomontanum, with each species possessing 126 genes with 84 protein coding genes (PCGs). While genomic rearrangements were absent, structural variation was detected in the LSC/IR/SSC boundaries. Five pseudogenes were identified, among which $\Psi r p s 19$ and $\Psi y c f 1$ were in the LSC/IR/SSC boundaries, $\Psi r p s 16$ and $\Psi$ infA in the LSC region, and $\Psi y c f 15$ in the IRb region. The nucleotide variability (Pi) of Aconitum was estimated to be 0.00549 , with comparably higher variations in the LSC and SSC than the IR regions. Eight intergenic regions were revealed to be highly variable and a total of $58-62$ simple sequence repeats (SSRs) were detected in all three species. More than $80 \%$ of SSRs were present in the LSC region. Altogether, $64.41 \%$ and $46.81 \%$ of SSRs are mononucleotides in subg. Lycoctonum and subg. Aconitum, respectively, while a higher percentage of di-, tri-, tetra-, and penta- SSRs were present in subg. Aconitum. Most species of subg. Aconitum in Eastern Asia were first used for phylogenetic analyses. The availability of the complete cp genome sequences of these species in subg. Lycoctonum will benefit future phylogenetic analyses and aid in germplasm utilization in Aconitum species. 


\section{INTRODUCTION}

48 The chloroplast (cp) is an intracellular organelle that plays an important role in the process of

49 photosynthesis and it is widely present in algae and plants (Neuhaus \& Emes, 2000; Inoue, 2011).

50 The cp genome in angiosperms is a circular DNA molecule with a typically quadripartite

51 structure, consisting of two copies of a large inverted repeat (IR) region that separates a large-

52 single-copy (LSC) region from a small-single-copy (SSC) region (Raubeson \& Jansen, 2005;

53 Yang et al., 2010; Gree, 2011; Wicke et al., 2011). Although highly conserved among plants,

54 some differences in gene synteny, copy number and pseudogenes have been observed in $\mathrm{cp}$ genome structures (Shradha et al., 2010; Lei et al., 2016; Ivanova et al., 2017). A complete cp genome is valuable for plant taxonomical analyses, phylogenetic reconstructions, speciation

processes, and biogeographical inferences at different taxonomic levels. The cp genome is useful in investigating the maternal origin in plants, especially those with polyploid species, due to their haploid maternal inheritance and high conservation in gene content and genome structure (Birky, 1995; Soltis \& Soltis, 2000; Song et al, 2002). High-throughput sequencing technologies have enabled a rapid increase in the completion of $\mathrm{cp}$ genomes and have shifted the study of phylogenetics to phylogenomics. Highly informative universal markers based on indels, substitutions, and inversions of the $\mathrm{cp}$ genome have been further developed for various molecular studies in plants.

The genus Aconitum L. belongs to the tribe Delphinieae in the Ranunculaceae family and represents one of the earliest diverging lineages within the eudicots APG IV (Wang et al., 2009; Sun et al., 2011; The Angiosperm Phylogeny Group, 2016). It is currently divided into two subgenera, A. subgenus Lycoctonum and A. subgenus Aconitum, comprising about more than 400 species throughout Eurasia and North America with its diversification center in Eastern Asia 
70 (Utelli, Roy \& Baltisberger; 2000; Jabbour \& Renner, 2012; Wang et al., 2013). Polyploid

71 species were identified in both subgenera, particularly in subg. Lycoctonum. One of the tetraploid

72 species in subg. Lycoctonum is A. angustius $(2 \mathrm{n}=4 \mathrm{x}=32)$, which possesses heterologous

73 chromosomes and is hypothesized to be a hybrid of $A$. finetianum $(2 \mathrm{n}=2 \mathrm{x}=16)$ and $A$.

sinomontanum $(2 \mathrm{n}=2 \mathrm{x}=16)($ Gao, 2009; Kong et al., 2017b). The three species display

intermediate morphological characteristics and overlapping geographical distributions (Shang \& Lee, 1984; Yuan \& Yang, 2006; Gao, 2009; Gao, Ren \& Yang, 2012). Based on previous morphological analysis and phylogenetic inference, A. finetianum was inferred to be the putative maternal progenitor of A. angustius (Gao, 2009; Kong et al., 2017b).

The genus Aconitum is known as a taxonomically and phylogenetically challenging taxon. Early divergence between subg. Lycoctonum and subg. Aconitum in Europe was suggested based on trnH-psbA and ITS (Utelli, Roy \& Baltisberger; 2000). Although high morphological variability within and among populations was detected due to recent speciation, the morphological characteristics are poor indicators of relatedness. Jabbour \& Renner (2012) conducted a phylogenetic reconstruction focusing on Delphineae based on $\operatorname{trn} \mathrm{L}-\mathrm{F}$ and ITS that suggested Aconitum was monophyletic clade and a sister group of Delphinium. However, few species from Eastern Asia were used, which may have affected the previous phylogenetic analysis. Most recently, phylogenetic inferences of polyploid species relationships in subg. Lycoctonum were made using four cpDNA intergenic regions $(n d h \mathrm{~F}-\operatorname{trn} \mathrm{L}, p s b \mathrm{~A}-\operatorname{tr} n \mathrm{H}, p s b \mathrm{D}-\operatorname{tr} n \mathrm{~T}$, and trnT-L) and two nrDNA regions (ITS and ETS) (Kong et al., 2017b), Aconitum finetianum was inferred as the maternal progenitor of $A$. angustius. With the same cpDNA intergenic regions, taxonomical revision has been conducted based on phylogenetic analyses of subg. Lycoctonum by Hong et al. (2017), yet phylogenetic information at the genomics level has been 
93 absent.

94 Although some Aconitum species are highly toxic because of aconite alkaloid, many species

95 are essential in the formulation of traditional herbal medicine in Asia (Zhao et al., 2010;

96 Semenov et al., 2016; Wada et al., 2016; Liang et al., 2017). The current state of Aconitum

97 phylogenetics lacks molecular information of some species in Eastern Asia, and thus inhibits

98 identification and germplasm utilization of this genus. In this study, we report the complete cp

99 genome sequences of three species in subg. Lycoctonum; we established and characterized the

100 organization of the cp genome sequences of tetraploid $A$. angustius as well as diploid $A$.

101 finetianum and A. sinomontanum. We further compared the structure, gene arrangement and

102 microsatellite repeats (SSRs) with the related species in both subgenera of Aconitum. Altogether,

10314 species and 2 varieties from Aconitum were used for phylogenetic reconstruction at the

104 genomic level. Seven previously unanalyzed species from the subg. Aconitum in Eastern Asia

105 were investigated for phylogenetic relationships, and the maternal origin of $A$. finetianum was

106 explored in the tetraploid, A. angustius. Our results provide cp genomic information for

107 taxonomical identification, phylogenetic inference, or the population history of Aconitum or

108 Ranunculaceae, which can also aid in the utilization of the genetic resources of Aconitum as a

109 traditional herbal medicine.

111 MATERIALS AND METHODS

112 Plant samples and DNA extraction

113 Fresh leaves were collected from A. angustius, A. finetianum and A. sinomontanum growing in

114 the greenhouse of South China Botanical Garden, Chinese Academy of Sciences. Total genomic 115 DNA was extracted from the fresh leaves of $A$. angustius, A. finetianum and A. sinomontanum 
116

117

118

119

120

121

122

123

124

125

using the modified CTAB method (Dolye \& Dolye, 1987). The DNA concentration was quantified using a Nanodrop spectrophotometer (Thermo Scientific, Carlsbad, CA, USA), and a final DNA concentration of $>30 \mathrm{ng} / \mu \mathrm{L}$ was used for Illumina sequencing.

\section{Chloroplast genome sequencing, assembly and annotation}

We sequenced the complete cp genome of $A$. angustius, A. finetianum and A. sinomontanum with an Illumina HiSeq 2000 at Beijing Genomics Institute (BGI) in Wuhan, China. Genomic DNA was fragmented randomly and then the required length of DNA fragments was obtained by electrophoresis. Adapters were ligated to DNA fragments followed by cluster preparation and sequencing. A paired-end library was constructed with $270 \mathrm{bp}$ insert size, and then $150 \mathrm{bp}$ paired reads were sequenced using an Illumina HiSeq 2000.

We assembled the cp genomes using Geneious 9.1.4 (Biomatters Ltd., Auckland, New Zealand) with BLAST and map reference tools, respectively. Using the program DOGMA (http://dogma.ccbb.utexas.edu/) (Wyman, Jansen \& Boore, 2004) and Geneious, annotation was performed in comparison with the cp genomes of A. reclinatum (MF186593) (Kong et al., 2017a), A. barbatum var. puberulum (KC844054) (Chen et al., 2015), and A. barbatum var. hispidum (KT820664) in subg. Lycoctonum as well as 10 species from the subg. Aconitum (Choi et al., 2016; Kim et al., unpublished; Lim et al., 2017; Yang, unpublished; Yang et al., unpublished) (Table 1). Altogether, 14 species and 2 varieties in both subgenera of Aconitum were used for annotation (Table 1). Among those species, A. angustius, A. finetianum, A. sinomontanum, A. barbatum var. hispidum, and A. barbatum var. puberulum were collected from China (Chen et al., 2015), A. reclinatum came from the United States (Kong et al., 2017a), while the remaining species were all sampled from Korea (Choi et al., 2016; Kim et al., unpublished; 
139 Lim et al., 2017; Yang, unpublished; Yang et al., unpublished). Chloroplast genome sequences of

140 Aconitum species from Europe were not available in GenBank.

141 The annotation of tRNA genes were confirmed using the ARAGORN program (Laslett \&

142 Canback, 2004), and then manually adjusted using the program Geneious. Contigs with BLAST

143 hits to consensus sequence from the "map to reference function" were assembled manually to 144 construct complete chloroplast genomes. Finally, the circular genome maps of the three species 145 were illustrated using the Organellar Genome DRAW tool (OGDRAW, http://ogdraw.mpimp146 golm.mpg.de/) (Lohse et al., 2013). The annotated chloroplast genomic sequences of $A$. 147 angustius, A. finetianum and A. sinomontanum have been submitted to GenBank (Accession 148 Number: MF155664, MF155665 and MF155666).

\section{Genome comparison and divergence hotspot}

151

152

153

154

155

156

157

158

159

160

161

The cp genome sequences from the finalized data set were aligned with MAFFT v7.0.0 (Katoh \& Standley, 2012) and adjusted manually when necessary. Based on many other cp genome studies, the IRs expansion/contraction could lead to changes in the structure of the cp genome, leading to the length variation of angiosperm cp genomes and contributing to the formation of pseudogenes (Kim \& Lee, 2004; Nazareno, Carlsen \& Lohmann, 2015; Ivanova et al., 2017). Therefore, we conducted comparative analysis to detect the variation in the LSC/IR/SSC boundaries among the species/varieties. Comparative analysis of the nucleotide diversity $(\mathrm{Pi})$ among the complete $\mathrm{cp}$ genomes of Aconitum was performed based on a sliding window analysis using DnaSP 5.10 (Librado \& Rozas, 2009). The window length was 600 bp and step size was 200 bp. To test and visualize the presence of genome rearrangement and inversions, gene synteny was performed using MAUVE as implemented in Geneious with default settings based on 14 species and 2 
162 varieties in both subgenera.

163

164 Simple sequence repeats analysis

165 MISA (http://pgrc.ipk-gatersleben.de/misa/misa.html) (Thiel et al., 2003) is a tool for the 166 identification and location of perfect microsatellites and compound microsatellites (two 167 individual microsatellites, disrupted by a certain number of bases). We used MISA to search for 168 potential simple sequence repeats (SSRs) loci in the cp genomes of the three species. The 169 minimum number (thresholds) of SSRs was set as 10, 5, 4, 3, and 3 for mono-, di-, tri-, tetra-, 170 and penta-nucleotides SSRs, respectively. All of the repeats found were manually verified and 171 the redundant ones were removed.

172

\section{Phylogenetic analysis}

174 Four species and two varieties in subg. Lycoctonum and 10 species in subg. Aconitum were used 175 for phylogenetic reconstruction, with Megaleranthis saniculifolia and Clematis terniflorav as the outgroup. Except for A. kusnezoffii, A. volubile, and A. ciliare, the remaining seven species in subg. Aconitum from Korea were first used for phylogenetic analysis. The complete cp genome sequences and PCGs were used for the phylogenetic reconstruction of Aconitum species in Eastern Asia. Three different methods including Bayesian Inference (BI), Maximum Parsimony (MP), and Maximum Likelihood (ML) were employed. In all analyses, gaps were treated as missing.

Bayesian Inference (BI) of the phylogenies was performed using MrBayes v.3.2 183 (Huelsenbeck \& Ronquist, 2001; Ronquist \& Huelsenbeck, 2003). The best model was 184 determined for each sequence partition, after comparisons among 24 models of nucleotide 
185 substitution using Modeltest v.3.7 (Posada \& Crandall, 1998). We performed MP using PAUP* 186 v.4.0b10 (Swofford, 2002). We calculated the bootstrap values with 1000 bootstrap replicates, 187 each with 10 random sequence addition replicates holding a single tree for each run. We 188 conducted ML using RAxML (Stamatakis, 2006) and the RAxML graphical interface (raxmlGUI 189 v.1.3 (Silvestro \& Michalak, 2012) with 1000 rapid bootstrap replicates. The general time190 reversible (GTR) model was chosen with a gamma model for the rate of heterogeneity.

\section{RESULTS AND DISCUSSION}

193

194

195

196

197

198

199

200

201

202

203

204

205

206

207

\section{Genome Organization and Features}

Using the Illumina HiSeq 2000 sequencing platform, a total number of 2x150 bp pair-end reads ranging from $9,879,068$ to $27,530,148 \mathrm{bp}$ were produced for the three species in subg. Lycoctonum. Altogether, 1,270 Mb of clean data were produced for A. angustius, 3,586 Mb for A. finetianum, and 3,590 $\mathrm{Mb}$ for $A$. sinomontanum. The assembly generated an average of 6,713 contigs with a N50 length of 732 bp for A. angustius, an average of 6,201 contigs with a N50 length of $801 \mathrm{bp}$ bp for $A$. finetianum, and an average of 6,999 contigs with a N50 length of 769 bp for A. sinomontanum. Scaffolds from the assembly with k-mer values of 35 to 149 were matched to reference cp genome sequences, which were used to determine the relative position and direction respectively. We generated a new draft chloroplast genome by manually identifying the overlapping regions. To further refine the draft genome, the quality and coverage of each was double-checked by remapping reads. The complete $\mathrm{cp}$ genome sequences of the three species with full annotations were deposited into GenBank.

The size of the cp genomes was 156,109 bp for $A$. angustius, 155,625 bp for A. finetianum and 157,215 bp for A. sinomontanum (Table 1). The chloroplast genomes displayed a typical 
208 quadripartite structure, including a pair of IRs $(25,927-26,225$ bp) separated by LSC (86,664$20988,074 \mathrm{bp})$ and SSC (16,914-17,107 bp) regions (Fig. 1 and Table 1). The GC content of the

210 three cp genomes was 38.00\%, demonstrating congruence with other Aconitum species $(38.00 \%$ 211 or $38.10 \%)$ (Table 1$)$.

212 When duplicated genes in the IR regions were counted only once, each of the three cp 213 genomes encode 126 predicted functional genes, including 84 PCGs, 38 tRNA genes, and four 214 rRNA genes. The remaining non-coding regions include introns, intergenic spacers, and 215 pseudogenes. Altogether 18 genes were duplicated in the IR regions, including seven PCGs, 216 seven tRNA genes, and four rRNA genes (Fig. 1; Table S1). Each of the thirteen genes (eight

217 PCGs and five tRNA genes) contained one interval, and three PCGs (clpP, ycf3 and rps 12) had 218 two intervals each (Table S1). The maturase $\mathrm{K}$ (matK) gene in the cp genomes of the three 219 species is located within $\operatorname{trn} \mathrm{K}$ intron, which is similar in most of the other plants species (Kong $220 \&$ Yang, 2017). In the IR regions, the four rRNA genes and two tRNA genes (trnI and $\operatorname{trn} A)$ are 221 clustered as $16 \mathrm{~S}-\operatorname{trn} \mathrm{I}-\operatorname{trn} \mathrm{A}-23 \mathrm{~S}-4.5 \mathrm{~S}-5 \mathrm{~S}$. This has also been reported in the cp genomes of $A$. 222 barbatum var. hispidum, A. barbatum var. puberulum, and many other plant species (Mardanov 223 et al., 2008; Wu et al., 2014; Chen et al., 2015).

\section{Comparative analysis of genomic structure}

226 Synteny analysis identified a lack of genome rearrangement and inversions in the cp genome 227 sequences of the Aconitum species. No gene rearrangement and inversion events were detected 228 (Fig. S1). Genomic structure, including gene number and gene order, is highly conserved among 229 the Aconitum species; however, structural variation was still present in the LSC/IR/SSC 230 boundaries (Fig. 2). The genes rps19-rp12-trn $\mathrm{H}$ and $y c f 1-n d h \mathrm{~F}$ were located between the 
231 junction of the LSC/IR and SSC/IR regions. The rps 19 gene crosses the LSC/IRa junction region

232 in A. sinomontanum, A. barbatum var. puberulum and A. barbatum var. hispidum of subg.

233 Lycoctonum, as well as in A. jaluense, A. volubile, A. carmichaelii, A. kusnezoffii and $A$.

234 monanthum of subg. Aconitum. As a result, the rps19 gene has apparently lost its protein-coding

235 ability due to being partially duplicated in the IRb region, thus a producing pseudogenized

236 Yrps19 gene. The same was found with the $y c f 1$ gene, as the IRb/SSC junction region is located

237 within the $y c f 1$ CDS region and only a partial gene is duplicated in the IRa region, resulting in a

238 pseudogene. This is a general structure among the dicots. The $\Psi y c f 1$ pseudogene in the IR region

239 was 1,279 bp for two varieties in subg. Lycoctonum and seven species in subg. Aconitum.

240 However, length variation was present in the IR of the remaining six species: 1,292 bp in $A$.

241 angustius, $A$ sinomontanum, and $A$. reclinatum; 1,165 bp in $A$. finetianum; 1,274 bp in $A$.

242 chiisanense; 1,356 bp in A. volubile; and 1,263 bp in A. carmichaelii (Fig. 2; Table 2).

243 Three pseudogenes, $\Psi y c f 15, \Psi r p s 16$, and $\Psi$ infA, were identified in the gene annotations

244 (Table 2). The $\Psi y c f 15$ gene is pseudolized in A. austrokoreense and A. chiisanense with four

245 base insertions and pseudolized in A. monanthum with a one base insertion, contributing to

246 several internal stop codons. The IinfA region is pseudogenized with two nonsynonymous

247 substitutions producing internal stop codons in all of the members of subg. Lycoctonum. This

248 pseudogenized IinfA gene has also been found in other angiosperm chloroplast genomes

249 (Raman \& Park, 2015; Lu, Li \& Qiu, 2017). The gene rps16 encodes the ribosomal protein S16

250 and is present in the cp genome of most if the higher plants. However, rps 16 has been

251 functionally lost in various plant species (Shradha et al, 2010). A pseudogene Trps 16 was also

252 present in the cp genomes of $A$. angustius, $A$. finetianum and A. reclinatum in subg. Lycoctonum

253 as well as in the nine species in subg. Aconitum due to the loss of one CDS region (Table 2). As 
254 has been revealed in other studies, the functional loss of the rps16 gene might be compensated

255 by the dual targeting of the nuclear rps 16 gene product (Keller et al., 2017).

256

257

258

259

260

261

262

263

264

265

266

267

268

269

270

271

272

273

274

275 Characterization of simple sequence repeats

276 MISA was used to identify SSRs with minimum a of $10 \mathrm{bp}$ repeats among the three species. In $A$.

\section{Sequence divergence among the species in Aconitum}

The average nucleotide variability $(P i)$ values were estimated to be 0.00549 , ranging from 0 to 0.03856, based on the comparative analysis of cp genome sequences in Aconitum species. The highest variation was found in the LSC and SSC regions, with an average $P i=0.007140$ and 0.008368, respectively. The IR regions had a much lower nucleotide diversity with $P i=$ 0.001079 and 0.001459. Eight intergenic regions $(\operatorname{trn} \mathrm{H}-p s b \mathrm{~A}, \operatorname{trn\mathrm {K}}-r p s 16, \operatorname{trn} \mathrm{D}-\operatorname{trn} \mathrm{Y}, \operatorname{trn} \mathrm{Y}-\operatorname{trn} \mathrm{E}$, $\operatorname{trn} \mathrm{E}-t r n \mathrm{~T}, \operatorname{trn} \mathrm{T}-t r n \mathrm{~L}, r p l 12-c l p \mathrm{P}$ and $\operatorname{trn} \mathrm{H}-\operatorname{trn} \mathrm{R}$ ) were highly variable, with $P i$ value $\sim 0.023$ (Fig.

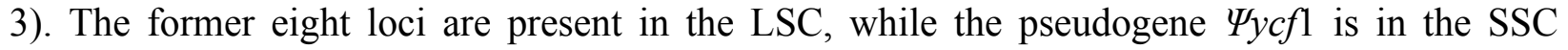
region. The single-copy regions have been demonstrated to be highly variable with loci clustered in 'hot spots' (Kong \& Yang, 2017). Among the eight intergenic regions, trnH-psbA and trnT$\operatorname{trn} \mathrm{L}$ are variable and useful for phylogenetic reconstruction in the subg. Lycoctonum (Utelli, Roy \& Baltisberger, 2000; Kong et al., 2017b). However, the other intergenic regions, even with higher nucleotide variability, have never been involved in the phylogenetic analysis for the genus Aconitum. The highly variable loci detected in the current study may provide a basis for further phylogenetic characterization of this genus. The observed divergence hotspot regions provide abundant information for marker development in phylogenetic analysis or conservation genetics of Aconitum. 
277 angustius, 60 SSRs were found, while 62 SSRs were found in A. finetianum, and 58 in $A$.

278 sinomontanum. This result is comparable with $A$. reclinatum (61 SSRs), A. barbatum var.

279 hispidum (53 SSRs), and A. barbatum var. puberulum (57 SSRs). An average of 59 SSRs were

280 identified in subg. Lycoctonum, which is relatively higher than that of subg. Aconitum (47). In

281 both subgenera, most SSRs are in the LSC regions, accounting for an average of $85.31 \%$ and $28280.85 \%$ in subg. Lycoctonum and subg. Aconitum, respectively. Among all of the SSRs, the 283 mononucleotide A/T repeat units occupied the highest proportion, with $64.41 \%$ and $46.82 \%$ of 284 the total SSRs in subg. Lycoctonum and subg. Aconitum, respectively. Although few SSRs were 285 detected in subg. Aconitum, a higher proportion of di-, tri-, tetra- and penta-nucleotide repeats 286 were detected (Table 3). The SSRs have a remarkably high A/T content with only seven SSRs, 287 namely $(\mathrm{ATCT})_{3},(\mathrm{TTCT})_{3},(\mathrm{CTTT})_{3},(\mathrm{TAAAG})_{3},(\mathrm{TTTC})_{3},(\mathrm{ATAC})_{3}$ and $(\mathrm{CATT})_{3}$, that contain 288 one $\mathrm{C}$ or $\mathrm{G}$ nucleotide.

289 A total of $11 \mathrm{cp} \mathrm{SSR} \mathrm{loci} \mathrm{were} \mathrm{shared} \mathrm{among} \mathrm{the} \mathrm{cp} \mathrm{genomes} \mathrm{of} \mathrm{tetraploid} \mathrm{A.} \mathrm{angustius} \mathrm{and}$ 290 diploid A. finetianum. No common cp SSRs were specifically found between A. angustius and $A$. sinomontanum. This result provides evidence of the maternal origin of the tetraploid $A$. angustius

292 293

from diploid A. finetianum, which is consistent with previous research (Gao, 2009; Kong et al., 2017b). Among the three species, the highest number of unique SSRs loci were present in $A$. sinomontanum (11) followed by A. angustius (7), A. finetianum (6), and A. reclinatum (5).

\section{Phylogenetic analyses}

In the present study, three phylogenetic methods (BI, MP and ML) resulted in identical phylogenetic trees within each data set. Different analyses based on the two datasets generated largely congruent topologies (Fig. 4). The total aligned length with parsimony informative loci 
300

301

302

303

304

305

306

307

308

309

310

311

312

313

314

315

316

317

318

319

320

321

322

was 178,392 bp with 4,342 for the complete cp genome sequences, and 106,535 bp with 3,164

for PCGs, respectively. All of the phylogenetic trees support that Aconitum comprises two monophyletic subgenera. High Bayesian posterior probabilities and bootstrap values were detected at most nodes, particularly based on the complete cp genomes (Fig. 4A).

The phylogenetic relationship of Korean species in subg. Aconitum was investigated for the first time. The monophyletic clade was formed by A. ciliare, A. carmichaelii, A. japonicum subsp. napiforme and A. kusnezoffii, with strong support values (Fig. 4). The clade comprised of $A$. jaluense subsp. jaluense and $A$. volubile exhibited moderate-to-high support, forming a monophyletic sister group. The positions of the four species A. ciliare, A. carmichaelii, A. austrokoreense, and A. chiisanense, demonstrated inconsistencies based on the two data sets. Obviously, these species received stronger support based on the sequences of the complete $\mathrm{cp}$ genome rather than PCGs, indicating that whole genomes are more efficient in determining phylogenetic relatedness in Aconitum than PCGs alone.

Based on the phylogenetic tree, the tetraploid $A$. angustius was always closely related with diploid A. finetianum, which further supports previous research (Kong et al., 2017b). The two species co-occur on several mountains in southeast China and even grow very closely within a community (Yuan \& Yang, 2006). They show similar morphological characteristics in having 3part leaves, the cylindric upper sepals and retrosely pubescent pedicels, resulting in common misidentification (Gao, Ren \& Yang, 2012). Aconitum finetianum is the most likely maternal progenitor of $A$. angustius based on both molecular phylogenetic and morphological evidence (Kong et al., 2017); therefore, it is reasonable to see that the two species have a close phylogenetic relationship. 
323 the evolution of $\Psi y c f 15$, it occurs in only three species $A$. monanthum, A. austrokoreense, and $A$.

324 chiisanense of subgen. Aconitum, which was probably pseudogenized once in each species

325 independently and subsequently restored to a functional copy. We propose that $\operatorname{Trps}_{16}$ was

326 pseudogenized during the divergence between the two subgenera and restored to a functional

327 copy within the $A$. sinomontanum-A. barbatum clade of subgen. Lycoctonum. With respect to

328 Trps 19, it appears to have been pseudogenized multiple times independently in phylogenetically

329 distant species of the two subgenera. $\Psi y c f 1$ is commonly found among cp genomes of plant

330 species. Within Aconitum, $\Psi y c f 1$ exhibits length variation and multiple convergent mutation

331 events, which are not consistent with the phylogenetic relationships of the genus. Only $\Psi \inf A$

332 shows an evolutionary history congruent with the phylogeny of Aconitum (Fig. 4B; Table 2).

333 Overall, our results show that similarities among pseudo-gene sequences do not necessarily 334 predict phylogenetic relationships among species.

336 Acknowledgement

337 We would like to provide a special thank to Dr. Tongjian Liu for his assistance in lab work and 338 data analyses. We thank Dr. AJ Harris and LetPub (www.letpub.com) for their linguistic 339 assistance during the preparation of this manuscript.

\section{ADDITIONAL INFORMATION AND DECLARATIONS}

DNA Deposition

343 The following information was supplied regarding the deposition of DNA sequences: GenBank 344 accession number: MF155664, MF155665 and MF155666.

\section{Data Availability}


346 The following information was supplied regarding data availability: The raw data can be found

347 in https://doi.org/10.6084/m9.figshare.5092414.v1,

348 https://doi.org/10.6084/m9.figshare.5092420.v1 and with the GenBank accession numbers in

349 Table 1.

350 Supplemental Information

351 Supplemental information for this article can be found online.

352

353

354

355

356

357

358

359

360

361

362

363

364

365

366

367

\section{REFERENCES}

Birky CW. 1995. Uniparental inheritance of mitochondrial and chloroplast genes: mechanisms and evolution. Proceedings of the National Academy of Sciences of the United States of America 92(25):11331-11338 DOI 10.1073/pnas.92.25.11331.

Chen XC, Li QS, Li Y, Qian J, Han JP. 2015. Chloroplast genome of Aconitum barbatum var. puberulum (Ranunculaceae) derived from CCS reads using the PacBio $R S$ platform. Frontiers in Plant Science 6(42):1-9 DOI 10.3389/fpls.2015.00042.

Choi JE, Kim GB, Lim CE, Yu HJ, Mun JH. 2016. The complete chloroplast genome of Aconitum austrokoreense Koidz. (Ranunculaceae), an endangered endemic species in Korea. Mitochondrial DNA B Resour 1(1): $\quad 688-689$ DOI $10.1080 / 23802359.2016 .1219644$

Doyle JJ, Doyle JL, Rausher J, Brown AHD. 2004. Diploid and polyploid reticulate evolution throughout the history of the perennial soybeans (Glycine subgenus Glycine). New Phytologist 161:121-132 DOI 10.1046/j.1469-8137.2003.00949.x.

Gao Q. 2009. Taxonomic revision of Aconitum L. subgenus Lycoctonum (DC.) Peterm. (Ranunculaceae) from China. D. Phil. Thesis, Institute of Botany, the Chinese Academy 
369

370

371

372

373

374

375

376

377

378

379

380

381

382

383

384

385

386

387

388

389

390

391

of Sciences, Beijing, China

Gao Q, Ren C, Yang QE. 2012. Taxonomic status and distributional range of Aconitum angustius (Ranunculaceae) based on cytological evidence. Nordic Journal of Botany 30:1-13 DOI 10.1111/j.1756-1051.2012.01506.x.

Green BR. 2011. Chloroplast genomes of photosynthetic eukaryotes. the Plant Journal 66:3444 DOI 10.1111/j.1365-313X.2011.04541.x.

Hong Y, Luo Y, Gao Q, Ren C, Yuan Q, Yang QE. 2017. Phylogeny and reclassification of Aconitum subgenus Lycoctonum (Ranunculaceae). PLoS ONE 12(1):e0171038 DOI 10.1371/journal.pone.0171038.

Huelsenbeck JP, Ronquist F. 2001. MRBAYES: Bayesian inference of phylogenetic trees. Bioinformatics 17:754-755 DOI 10.1093/bioinformatics/17.8.754.

Inoue K. 2011. Emerging roles of the chloroplast outer envelope membrane. Trends in Plant Science 16(10):550-557 DOI 10.1016/j.tplants.2011.06.005.

Ivanova Z, Sablok, G, Daskalova E, Zahmanova G, Apostolova E, Yahubyan G, Baev V. 2017. Chloroplast genome analysis of resurrection Tertiary relic Haberlea rhodopensis highlights genes important for desiccation stress response. Frontiers of Plant Sciences 8:204 DOI 10.3389/fpls.2017.00204.

Jabbour F, Renner SS. 2012. A phylogeny of Delphinieae (Ranunculaceae) shows that Aconitum is nested within Delphinium and that Late Miocene transitions to long life cycles in the Himalayas and Southwest China coincide with bursts in diversification. Molecular Phylogenetics and Evolution 62:928-942 DOI 10.1016/j.ympev.2011.12.005.

Katoh K, Frith MC. 2012. Adding unaligned sequences into an existing alignment using $\begin{array}{llll}\text { MAFFT and } & \text { LAST. } & \text { Bioinformatics }: 3144-3146 & \text { DOI }\end{array}$ 
392

393

394

395

396

397

398

399

400

401

402

403

404

405

406

407

408

409

410

411

412

413

414

10.1093/bioinformatics/bts578.

Kearse M, Moir R, Wilson, Stones-Havas S, Cheung M, Sturrock S, Buxton S, Cooper A, Markowitz S, Duran C, Thierer T, Ashton B, Meintjes P, Drummond A. 2012. Geneious Basic: an integrated and extendable desktop software platform for the organization and analysis of sequence data. Bioinformatics 28:1647-1649 DOI 10.1093/bioinformatics/bts199.

Keller J, Rousseau-Gueutin M, Martin GE, Morice J, Boutte J, Coissac E, Ourari M, Aïnouche M, Salmon A, Cabello-Hurtado F, Aïnouche A. 2017. The evolutionary fate of the chloroplast and nuclear rps 16 genes as revealed through the sequencing and comparative analyses of four novel legume chloroplast genomes from Lupinus. DNA Research in press DOI 10.1093/dnares/dsx006.

Kim KJ, Lee HL. 2004. Complete chloroplast genome sequences from Korean ginseng (Panax schinseng Nees) and comparative analysis of sequence evolution among 17 vascular plants. DNA Research 11:247-261 DOI 10.1093/dnares/11.4.247.

Kim GB, Lim CE, Mun JH. Unpublished. Complete chloroplast genomes of Aconitum species from Korea.

Kong WQ, Yang JH. 2017. The complete chloroplast genome sequence of Morus cathayana and Morus multicaulis, and comparative analysis within genus Morus L. PeerJ 5:e3037 DOI 10.7717/peerj.3037.

Kong HH, Liu WZ, Yao G, Gong W. 2017a. Characterization of the whole chloroplast genome of a rare and endangered species Aconitum reclinatum (Ranunculaceae) in the United States. Conservation Genetics Resources in press DOI 10.1007/s12686-017-0789-y

Kong HH, Zhang Y, Hong Y, Barker MS. 2017b. Multilocus phylogenetic reconstruction 
415

416

417

418

419

420

421

422

423

424

425

426

427

428

429

430

431

432

433

434

435

436

437

informing polyploid relationships of Aconitum subgenus Lycoctonum (Ranunculaceae) in China. Plant Systematics and Evolution 303:727-744 DOI 10.1007/s00606-0171406-y.

Laslett D, Canback B. 2004. ARAGORN, a program to detect tRNA genes and tmRNA genes in nucleotide sequences. Nucleic Acids Research 32:11-16 DOI 10.1093/nar/gkh152.

Lei WJ, Ni DP, Wang YJ, Shao JJ, Wang XC, Yang D, Wang JS, Chen HM, Liu C. 2016. Intraspecific and heteroplasmic variations, gene losses and inversions in the chloroplast genome of Astragalus membranaceus. Scientific Reports 6:21669 DOI $10.1038 / \operatorname{srep} 21669$.

Liang X, Chen L, Song L, Fei W, He M, He C, Yin Z. 2017. Diterpenoid alkaloids from the root of Aconitum sinchiangense W. T. Wang with their antitumor and antibacterial activities. Natural Product Research 11:1-8 DOI 10.1080/14786419.2016.1272113

Librado P, Rozas J. 2009. DnaSP v5: a software for comprehensive analysis of DNA polymorphism data. Bioinformatics 25:1451-1452 DOI 10.1093/bioinformatics/btp187.

Lim CE, Kim GB, Baek S, Han SM, Yu HJ, Mun JH. 2017. The complete chloroplast genome of Aconitum chiisanense Nakai

(Ranunculaceae). Mitochondrial DNA A 28(1):75-76 DOI: 10.3109/19401736.2015.1110805.

Lohse M, Drechsel O, Kahlau S, Bock R. 2013. OrganellarGenomeDRAW - a suite of tools for generating physical maps of plastid and mitochondrial genomes and visualizing expression data sets. Nucleic Acids Research 41(W1):W575-W581 DOI 10.1093/nar/gkt289.

Lu RS, Li P, Qiu YX. 2017. The Complete Chloroplast Genomes of Three Cardiocrinum (Liliaceae) Species: Comparative Genomic and Phylogenetic Analyses. Frontiers of 
438

439

440

441

442

443

444

445

446

447

448

449

450

451

452

453

454

455

456

457

458

459

460

Plant Sciences 7:2054 DOI 10.3389/fpls.2016.02054

Mardanov AV, Ravin NV, Kuznetsov BB, Samigullin TH, Antonov AS, Kolganova TV, Skyabin KG. 2008. Complete sequence of the duckweed (Lemna minor) chloroplast genome: structural organization and phylogenetic relationships to other angiosperms. Journal of Molecular Evolution 66:555-564 DOI 10.1007/s00239-008-9091-7

Nazareno AG, Carlsen M, Lohmann, LG. 2015. Complete chloroplast genome of Tanaecium tetragonolobum: the first Bignoniaceae plastome. PLoS ONE 10:e129930 DOI 10.1371/journal.pone.0129930.

Neuhaus H, Emes M. 2000. Nonphotosynthetic metabolism in plastids. Annual Review of Plant Biology 51:111-140 DOI 10.1146/annurev.arplant.51.1.111.

Posada D, Crandall KA. 1998. Modeltest: testing the model of DNA substitution. Bioinformatics 14:817-818 DOI 10.1093/bioinformatics/14.9.817.

Raubeson LA, Jansen RK. 2005. Chloroplast genomes of plants. In: Henry RJ, ed. Plant Diversity and Evolution: Genotypic and Phenotypic Variation in Higher Plants. Cambridge: CABI Press, 45-68.

Roman G, Park S. 2015. Analysis of the Complete Chloroplast Genome of a Medicinal Plant, Dianthus superbus var. longicalyncinus, from a Comparative Genomics Perspective. 10(10): e0141329 DOI 10.1371/journal.pone.0141329.

Ronquist F, Huelsenbeck JP. 2003. MrBayes 3: Bayesian phylogenetic inference under mixed models. Bioinformatics 19:1572-1574 DOI 10.1093/bioinformatics/btg180.

Roy S, Ueda M, Kadowaki K, Tsutsumi N. 2010. Different status of the gene for ribosomal protein S16 in the chloroplast genome during evolution of the genus Arabidopsis and closely related species. Genes and Genetic Systems 85:319-326 DOI 
461

462

463

464

465

466

467

468

469

470

471

472

473

474

475

476

477

478

479

480

481

482

483

10.1266/ggs.85.319.

Semenov AA, Enikeev AG, Snetkova LV, Permyakov AV, Sokolova NA, Dudareva LV. 2016. Ortho-phthalic acid esters in lipophilic extract from the cell culture of Aconitum baicalense Turcz ex Rapaics 1907. Doklady Biochemistry and Biophysics 471:421-422 DOI 10.1134/S1607672916060120.

Shang XM, Lee CL. 1984. Chromosome studies of ten species of Aconitum in China. Acta Phytotaxonomica Sinica 22:378-385

Silvestro D, Michalak I. 2012. raxmlGUI: a graphical front-end for RAxML. Organisms Diversity \& Evolution 12:335-337 DOI 10.1007/s13127-011-0056-0.

Soltis PS, Soltis DE. 2000. The role of genetic and genomic attributes in the success of polyploids. Proceedings of the National Academy of Sciences of the United States of America 97(13):7051-7057 DOI 10.1073/pnas.97.13.7051.

Song BH, Wang XQ, Wang XR, Sun LJ, Hong DY, Peng PH. 2002. Maternal lineages of Pinus densata, a diploid hybrid. Molecular Ecology 11:1057-1063 DOI 10.1046/j.1365294X.2002.01502.x.

Stamatakis A. 2006. RAxML-VI-HPC: maximum likelihood-based phylogenetic analyses with thousands of taxa and mixed models. Bioinformatics 22:2688-2690

Sun G, Dilcher DL, Wang HS, Chen ZD. 2011. A eudicot from the Early Cretaceous of China. Nature 471:625-628 DOI 10.1038/nature09811.

Swofford DL. 2002. PAUP*: Phylogenetic analysis using parsimony (* and other methods). Version 4.0b10, Sinauer Associates, Sunderland, Massachusets, USA

The Angiosperm Phylogeny Group. 2016. An update of the Angiosperm Phylogeny Group classification for the orders and families of flowering plants: APG IV. Botanical Journal 
of the Linnean Society 181:1-20 DOI 10.1111/boj.12385.

485

486

487

488

489

490

491

492

493

494

495

496

497

498

499

500

501

502

503

504

505

506

Thiel T, Michalek W, Varshney R, Graner A. 2003. Exploiting EST databases for the development and characterization of gene-derived SSR-markers in barley (Hordeumvulgare L.). Theoretical Application of Genetics 106:411-422 DOI 10.1007/s00122-002-1031-0.

Utelli AB, Roy BA, Baltisberger M. 2000. Molecular and morphological analyses of European Aconitum species (Ranunculaceae) Plant Systematics and Evolution 224:195-212 DOI 10.1007/BF00986343.

Wada K, Takeda K, Haraguchi M, Abe Y, Kuwahara N, Suzuki S, Terui A, Masaka T, Munakata N, Uchida M, Nunokawa M, Yamashita H, Goto M, Lee KH. 2016. Four new diterpenoid alkaloids from Aconitum japonicum. Planta Medica 81(S01):S1-S381 DOI $10.1055 / \mathrm{s}-0036-1596757$

Wang W, Liu Y, Yu SX, Gao TG, Chen ZD. 2013. Gymnaconitum, a new genus of Ranunculaceae endemic to the Qinghai-Tibetan Plateau. Taxon 62:713-722 DOI 10.12705/624.10.

Wang W, Lu AM, Ren Y, Endress ME, Chen ZD. 2009. Phylogeny and classification of Ranunculales: Evidence from four molecular loci and morphological data. Perspectives in Plant Ecology Evolution and Systematics 11:81-110 DOI 10.1016/j.ppees.2009.01.001.

Wicke S, Schneeweiss GM, dePamphilis, CW, Müller, KF, Quandt D. 2011. The evolution of the plastid chromosome in land plants: gene content, gene order, gene function. Plant Molecular Biology 76:273-297 DOI 10.1007/s11103-011-9762-4.

Wu Z, Gui S, Quan Z, Pan L, Wang S, Ke W, Liang D, Ding Y. 2014. A precise chloroplast 
507

508

509

510

511

512

513

514

515

516

517

518

519

520

521

genome of Nelumbo nucifera (Nelumbonaceae) evaluated with Sanger, Illumina MipSeq, and PacBio RS II sequencing platforms: insight into the plastid evolution of basal eudicots. BMC Plant Biology 14:289 DOI 10.1186/s12870-014-0289-0.

Wyman SK, Jansen RK, Boore JL. 2004. Automatic annotation of organellar genomes with DOGMA. Bioinformatics 20(17):3252-3255 DOI 10.1093/bioinformatics/bth352.

Yang M, Zhang XW, Liu GM, Yin YX, Chen KF, Yun QZ, Zhao DJ, Al-Mssallem IS, Yu J. 2010. The Complete Chloroplast Genome Sequence of Date Palm (Phoenix dactylifera L.). PLoS ONE 5(9):e12762 DOI 10.1371/journal.pone.0012762.

Yuan Q, Yang QE. 2006. Polyploidy in Aconitum subgenus Lycoctonum (Ranunculaceae). Botanical Journal of the Linnean Society 150:343-353 DOI 10.1111/j.10958339.2006.00468.x.

Zhao Y, Bu G, Zhou Y, Lv L, Yan G, Chen B, Wang L, Cen X. 2010. Mechanism study of Aconitum-induced neurotoxicity in PC12 cells: involvement of dopamine release and oxidative damage. Neurotoxicology 31:752-757 DOI 10.1016/j.neuro.2010.06.005. 


\section{Figure 1 (on next page)}

Figure 1. The gene maps of Aconitum angustius, $A$. finetianum, and $A$. sinomontanum.

The genes lying inside and outside the circles are transcribed in the clockwise and counterclockwise directions, respectively. Different colors denote the genes belonging to different functional groups. The thicknesses indicate the extent of the inverted repeats (IRa and IRb) that separate the small single-copy (SSC) region from the large single-copy (LSC) region. The dark gray in the inner circle corresponds to GC content, and the light gray to AT content. 


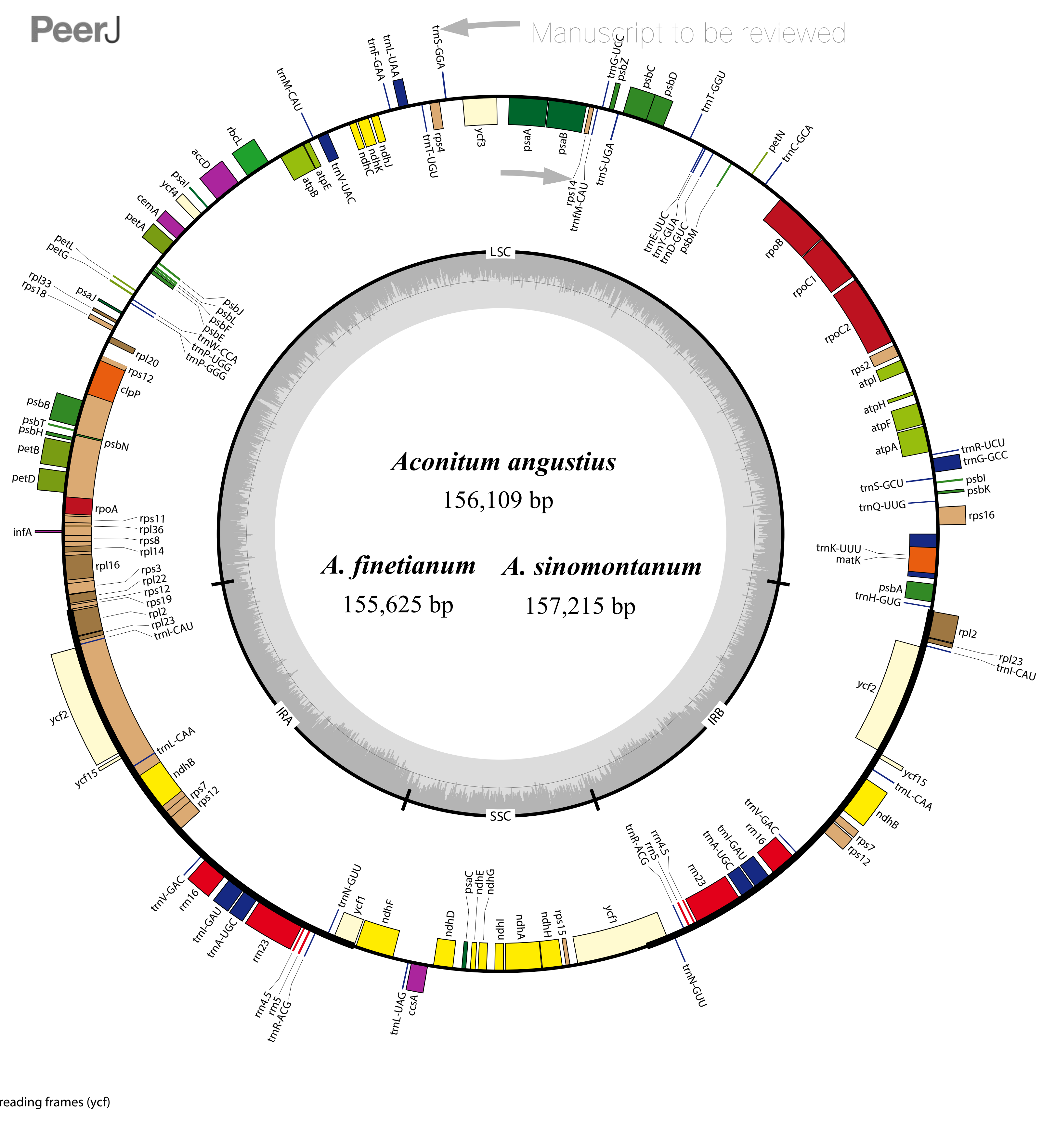


Figure 2 (on next page)

Figure 2. Comparison of the border positions of LSC, SSC and IR repeat regions among fourteen species and two varieties in Aconitum.

Genes are denoted by grey boxes and the gaps between the genes and the boundaries are indicated by the base lengths (bp). Extensions of the genes are also indicated above the boxes. 


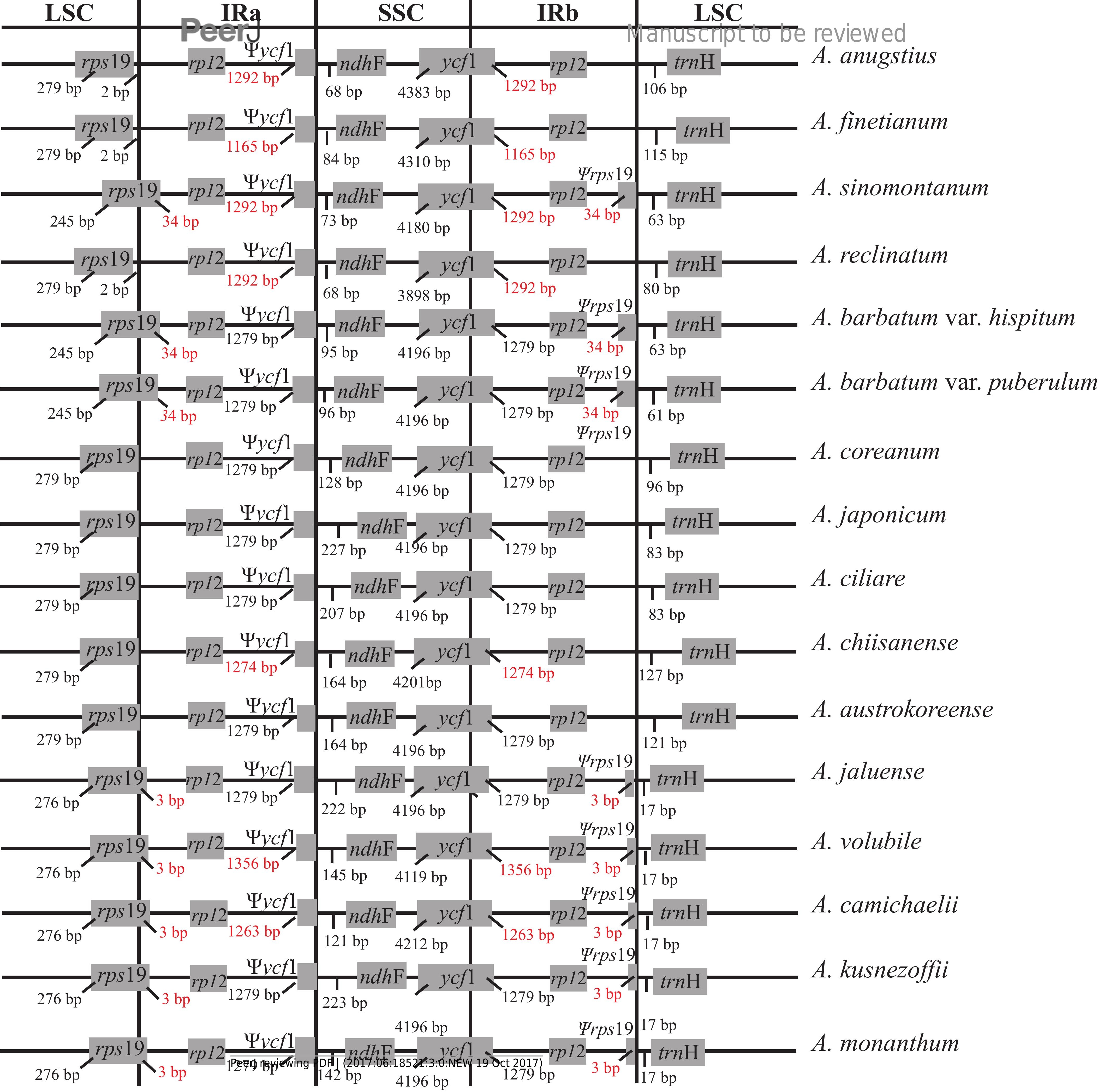




\section{Figure 3 (on next page)}

Figure 3. Sliding window analysis of the whole $\mathrm{cp}$ genome for fourteen species and two varieties in Aconitum.

$X$-axis: position of the midpoint of a window; $Y$-axis: nucleotide diversity (Pi) of each window. 


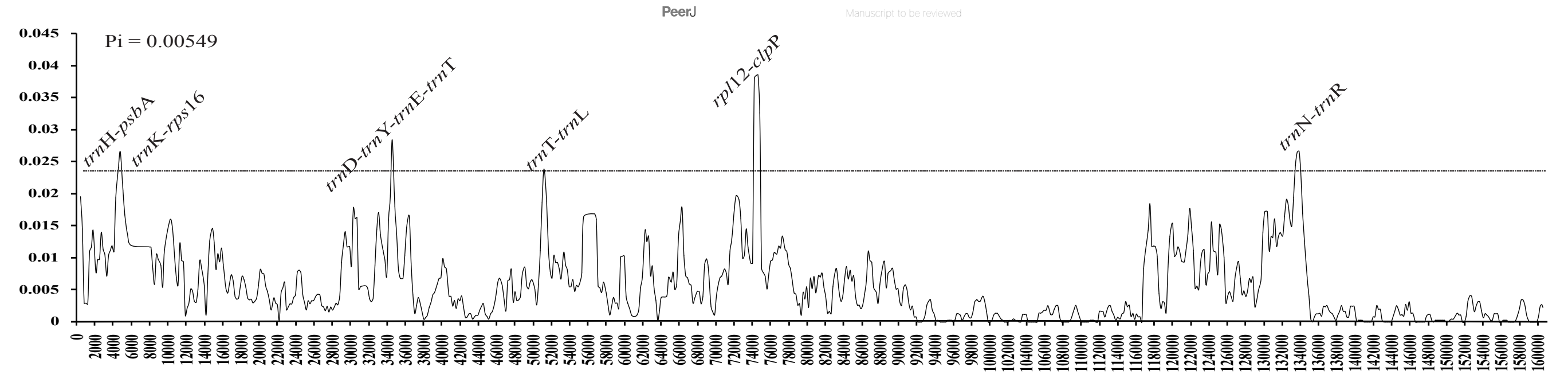


Figure 4 (on next page)

Figure 4. Phylogenetic relationship among Aconitum species.

Based on the two data sets of complete cp genome sequences (A) and PCGs (B), respectively, phylogenetic reconstruction was conducted using three methods: Bayesian Inference (BI), Maximum Parsimony (MP) and Maximum Likelihood (ML). Numbers above the branches represent BI posterior probabilities, MP and ML bootstrap values. The pseudogenes are indicated above the branches in different colors on the phylogenetic tree based on PCGs (B). 


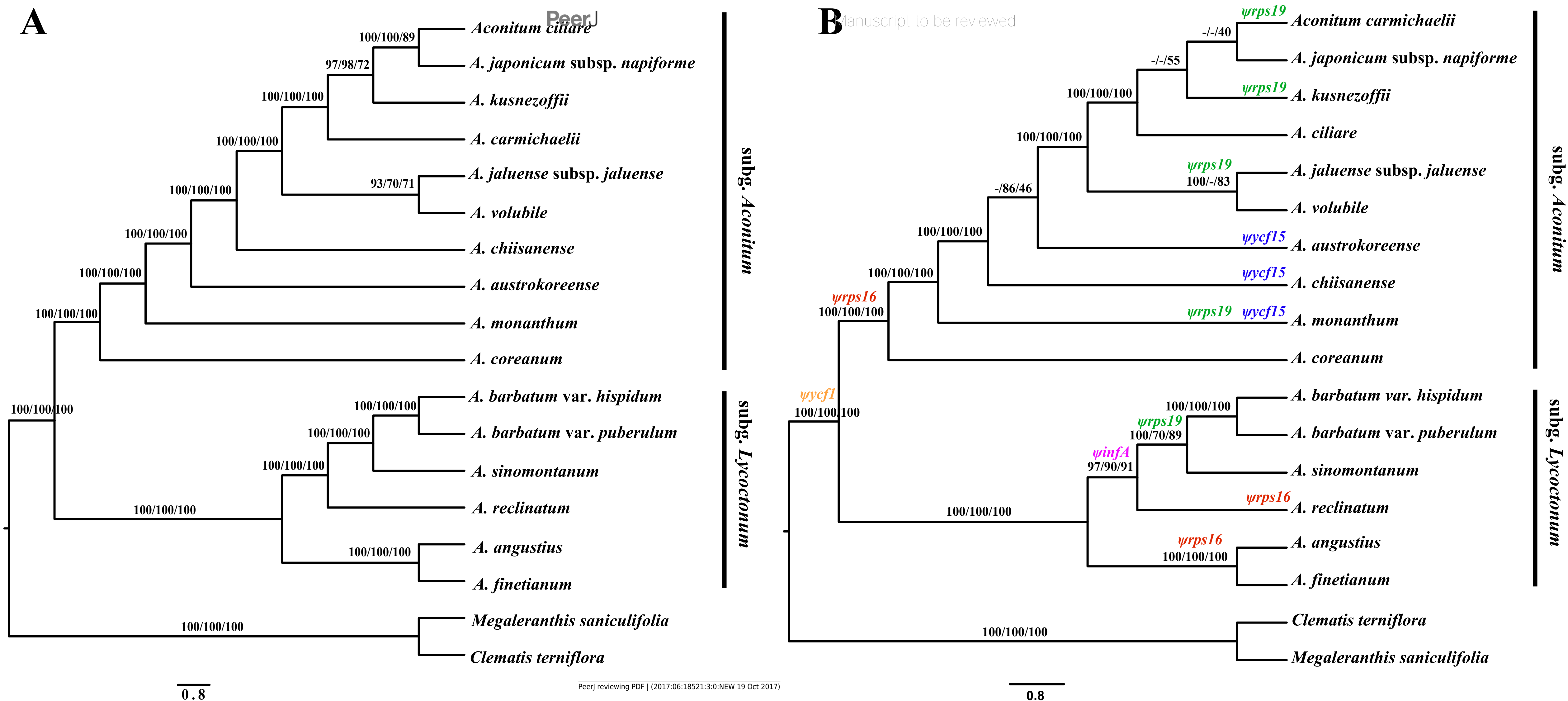




\section{Table $\mathbf{1}$ (on next page)}

Table 1. Summary of characteristics in chloroplast genome sequences of thirteen species and two varieties in Aconitum. 
1 Table 1 Summary of characteristics in chloroplast genome sequences of thirteen species and two varieties in Aconitum.

\begin{tabular}{|c|c|c|c|c|c|c|c|c|c|c|c|}
\hline & $\begin{array}{c}\text { GenBank } \\
\text { No. }\end{array}$ & $\begin{array}{c}\text { Voucher } \\
\text { Number/Herbarium }\end{array}$ & $\begin{array}{c}\text { Total } \\
\text { genome } \\
\text { size } \\
\text { (bp) }\end{array}$ & $\begin{array}{l}\text { LSC } \\
\text { (bp) }\end{array}$ & $\begin{array}{l}\text { SSC } \\
\text { (bp) }\end{array}$ & $\begin{array}{l}\text { IR } \\
\text { (bp) }\end{array}$ & $\begin{array}{c}\text { Total } \\
\text { number } \\
\text { of genes }\end{array}$ & $\begin{array}{l}\text { Protein-coding } \\
\text { genes }\end{array}$ & $\begin{array}{l}\text { tRNA } \\
\text { genes }\end{array}$ & $\begin{array}{l}\text { rRNA } \\
\text { genes }\end{array}$ & $\begin{array}{c}\text { GC } \\
\text { content }\end{array}$ \\
\hline \multicolumn{12}{|l|}{ subg. Lycoctonum } \\
\hline A. angustius & MF155664 & ZY37/IBSC & 156,109 & 86,719 & 16,914 & 26,225 & 126 & 84 & 38 & 4 & $38 \%$ \\
\hline A. finetianum & MF155665 & ZY25/IBSC & 155,625 & 86,664 & 17,107 & 25,927 & 126 & 84 & 38 & 4 & $38 \%$ \\
\hline A. sinomontanum & MF155666 & ZY46/IBSC & 157,215 & 88,074 & 16,926 & 26,090 & 126 & 84 & 38 & 4 & $38 \%$ \\
\hline A. reclinatum & MF186593 & US17/IBSC & 157,354 & 88,269 & 16,963 & 26,061 & 127 & 86 & 37 & 4 & $38 \%$ \\
\hline $\begin{array}{l}\text { A.barbatum } \\
\text { var. puberulum }\end{array}$ & KC844054 & Not provided/- & 156,749 & 87,630 & 16,941 & 26,089 & 127 & 85 & 38 & 4 & $38 \%$ \\
\hline $\begin{array}{l}\text { A.barbatum } \\
\text { var. hispidum }\end{array}$ & KT820664 & VP0000486327/NIBR & 156,782 & 87,661 & 16,987 & 26,067 & 127 & 85 & 38 & 4 & $38 \%$ \\
\hline subg. Aconitum & & & & & & & & & & & \\
\hline A. austrokoreense & KT820663 & VP0000494173/NIBR & 155,682 & 86,388 & 17,054 & 26,120 & 126 & 83 & 39 & 4 & $38.1 \%$ \\
\hline A.carmichaelii & KX347251 & ACAR20151205/- & 155,737 & 86,330 & 17,021 & 26,193 & 124 & 83 & 37 & 4 & $38.1 \%$ \\
\hline A. chiisanense & KT820665 & VP0000494177/NIBR & 155,934 & 86,559 & 17,085 & 26,145 & 125 & 82 & 39 & 4 & $38.1 \%$ \\
\hline A. ciliare & KT820666 & VP0000486323/NIBR & 155,832 & 86,452 & 17,084 & 26,148 & 126 & 83 & 39 & 4 & $38.1 \%$ \\
\hline A. coreanum & KT820667 & VP0000486326/NIBR & 157,029 & 87,622 & 17035 & 26,186 & 128 & 86 & 38 & 4 & $38.0 \%$ \\
\hline A. jaluense & KT820669 & VP0000494219/NIBR & 155,926 & 86,406 & 17,090 & 26,215 & 126 & 83 & 39 & 4 & $38.1 \%$ \\
\hline A. japonicum & KT820670 & VP0000494223/NIBR & 155,878 & 86,480 & 17,104 & 26,147 & 127 & 84 & 39 & 4 & $38.1 \%$ \\
\hline
\end{tabular}




\begin{tabular}{|c|c|c|c|c|c|c|c|c|c|c|c|}
\hline A. kusnezoffii & KT820671 & VP0000529885/NIBR & 155,862 & 86,335 & 17,103 & 26,212 & 126 & 84 & 39 & 4 & $38.1 \%$ \\
\hline A. monanthum & KT820672 & VP0000529886/NIBR & 155,688 & 86,292 & 16,996 & 26,200 & 125 & 82 & 39 & 4 & $38.1 \%$ \\
\hline A. volubile & KU556690 & $\begin{array}{l}\text { MBC_KIOM-2015- } \\
\text { 73/KIOM }\end{array}$ & 155,872 & 86,348 & 16,944 & 26,290 & 126 & 83 & 38 & 4 & $38.1 \%$ \\
\hline
\end{tabular}

2 


\section{Table 2 (on next page)}

Table 2. The distribution of the five pseudogenes in Aconitum. 
Table 2 The distribution of the five pseudogenes in Aconitum.

\begin{tabular}{|c|c|c|c|c|c|}
\hline Locations & $\mathbf{L S}$ & & LSC/IRa & IRa & IRa/SSC \\
\hline Genes & Yrps 16 & YinfA & Trps19 & $\Psi y c f 15$ & $\Psi y c f 1$ \\
\hline Aconitum subg. Lycoctonun & & & & & \\
\hline A. angustius & + & & & & $+/ 1292 b p$ \\
\hline A. finetianum & + & & & & $+/ 1165 b p$ \\
\hline A. sinomontanum & & + & $+/ 34 b p$ & & $+/ 1292 b p$ \\
\hline A. reclinatum & + & + & & & $+/ 1292 b p$ \\
\hline A. barbatum var. puberulum & & + & $+/ 34 b p$ & & $+/ 1279 b p$ \\
\hline A. barbatum var. hispidum & & + & $+/ 34 b p$ & & $+/ 1279 b p$ \\
\hline Aconitum subg. Aconitum & & & & & \\
\hline A. austrokoreense & + & & & $+/ 4 \mathrm{bp}$ indel & $+/ 1279 b p$ \\
\hline A. carmichaelii & + & & $+/ 3 b p$ & & $+/ 1263 b p$ \\
\hline A. chiisanense & + & & & $+/ 4 \mathrm{bp}$ indel & $+/ 1274 b p$ \\
\hline A. ciliare & + & & & & $+/ 1279 b p$ \\
\hline A. coreanum & + & & & & $+/ 1279 b p$ \\
\hline A. jaluense & + & & $+/ 3 b p$ & & $+/ 1279 b p$ \\
\hline A. japonicum & + & & & & $+/ 1279 b p$ \\
\hline A. kusnezoffii & + & & $+/ 3 b p$ & & $+/ 1279 b p$ \\
\hline A. monanthum & + & & $+/ 3 b p$ & $+/ 1$ bp indel & $+/ 1279 b p$ \\
\hline A. volubile & + & & $+/ 3 b p$ & & $+/ 1356 b p$ \\
\hline
\end{tabular}


$3+$ : indicating the presence of pseudogenes 


\section{Table 3(on next page)}

Table 3. Number of chloroplast SSRs in different regions or different types present in Aconitum species. 
Table 3 Number of chloroplast SSRs in different regions or different types present in Aconitum species.

\begin{tabular}{|c|c|c|c|c|c|c|c|c|c|}
\hline \multirow[t]{2}{*}{ Species } & \multirow[b]{2}{*}{ Homo $(>10)$} & \multirow[b]{2}{*}{ Di $(>5)$} & \multirow[b]{2}{*}{ Tri $(>5)$} & \multirow[b]{2}{*}{$\mathbf{T e}(>3)$} & \multirow[b]{2}{*}{ Pen $(>3)$} & \multicolumn{4}{|c|}{ Number of SSRs in different regions } \\
\hline & & & & & & LSC & SSC & IR & Total \\
\hline subg. Lycoctonum & $38(64.41 \%)$ & $10(16.95 \%)$ & $3(4.80 \%)$ & $8(12.99 \%)$ & $0(0.00 \%)$ & $50(85.31 \%)$ & $7(11.02 \%)$ & $2(3.39 \%)$ & 59 \\
\hline A. angustius & 40 & 9 & 2 & 8 & 1 & 50 & 8 & 2 & 60 \\
\hline A. finetianum & 42 & 9 & 2 & 8 & 1 & 51 & 9 & 2 & 62 \\
\hline A. sinomontanum & 36 & 12 & 2 & 8 & 0 & 50 & 6 & 2 & 58 \\
\hline A. reclinatum & 42 & 10 & 2 & 7 & 0 & 53 & 6 & 2 & 61 \\
\hline A.barbatum var. puberulum & 36 & 10 & 2 & 8 & 0 & 49 & 5 & 2 & 56 \\
\hline A.barbatum var.hispidum & 32 & 10 & 7 & 7 & 0 & 49 & 5 & 2 & 56 \\
\hline subg. Aconitum & $22(46.81 \%)$ & $15(31.91 \%)$ & $1(21.28 \%)$ & $7(14.89 \%)$ & $1(21.28 \%)$ & $38(80.85 \%)$ & $7(14.89 \%)$ & $2(4.36 \%)$ & 47 \\
\hline A. austrokoreense & 22 & 15 & 0 & 7 & 0 & 32 & 10 & 2 & 44 \\
\hline A.carmichaelii & 21 & 16 & 1 & 7 & 0 & 37 & 6 & 2 & 45 \\
\hline A. chiisanense & 21 & 16 & 1 & 7 & 2 & 39 & 6 & 2 & 47 \\
\hline A. ciliare & 23 & 16 & 1 & 7 & 1 & 41 & 5 & 2 & 48 \\
\hline A. coreanum & 39 & 14 & 1 & 7 & 1 & 50 & 10 & 2 & 62 \\
\hline A. jaluense & 17 & 14 & 1 & 6 & 2 & 33 & 6 & 2 & 41 \\
\hline A. japonicum & 20 & 16 & 1 & 7 & 1 & 37 & 6 & 2 & 46 \\
\hline A. volubile & 17 & 15 & 1 & 6 & 1 & 35 & 3 & 2 & 40 \\
\hline A. kusnezoffii & 19 & 16 & 1 & 7 & 1 & 37 & 5 & 2 & 44 \\
\hline
\end{tabular}


